\title{
Correction to: Effects of time-restricted feeding on body weight and metabolism. A systematic review and meta-analysis
}

\author{
Marianna Pellegrini $^{1} \cdot$ Iolanda Cioffi $^{2} \cdot$ Andrea Evangelista $^{3} \cdot$ Valentina Ponzo $^{1} \cdot$ Ilaria Goitre ${ }^{1} \cdot$ Giovannino Ciccone $^{3}$. \\ Ezio Ghigo ${ }^{1} \cdot$ Simona Bo ${ }^{1}$ (D)
}

Published online: 18 February 2020

(C) Springer Science+Business Media, LLC, part of Springer Nature 2020

\section{Correction to: Reviews in Endocrine and Metabolic Disorders https://doi.org/10.1007/s11154-019-09524-w}

The article "Effects of time-restricted feeding on body weight and metabolism. A systematic review and meta-analysis" written by Pellegrini Marianna, Cioffi Iolanda, Evangelista Andrea, Ponzo Valentina, Goitre Ilaria, Ciccone Giovannino, Ghigo Ezio, Bo Simona" was originally published with the surname and then first name of all authors. The correct presentation of author names is reflected above.

The original article has been corrected.

Publisher's note Springer Nature remains neutral with regard to jurisdictional claims in published maps and institutional affiliations.

The online version of the original article can be found at https://doi.org/ 10.1007/s11154-019-09524-w

Simona Bo

simona.bo@unito.it

1 Department of Medical Sciences, University of Turin, c.so AM Dogliotti 14, 10126 Turin, Italy

2 Clinical Medicine and Surgery, Federico II University Hospital, Naples, Italy

3 Unit of Clinical Epidemiology, CPO, "Città della Salute e della Scienza" Hospital of Turin, Turin, Italy 